\title{
The Functional Outcomes in Treatment of Distal Radio Ulnar Joint Injuries with Distal Radius Fractures
}

\author{
M.E.Abd Elnaby, E.A.Tabl and M.A.Eid \\ Orthopedic Surgery Dept., Faculty of Medicine, Benha Univ., Benha, Egypt \\ E-Mail: M.Eid @gmail.com
}

\begin{abstract}
Distal range breaks speak to the $10 \%-12 \%$ of all cracks of the body and as much as $72 \%$ of all lower arm cracks. Distal radioulnar joint (DRUJ) shakiness is a significant intricacy of distal span break and is significant reason for ulnar sided wrist torment in distal end sweep cracks. In this forthcoming examination twenty cases with crack distal range with distal radioulnar joint injury were overseen over the previous months between July 2019 and September 2020 in Benha University medical clinic and Shebin Elkom showing emergency clinic .. of 20 patients took on this investigation, Ten patients had been treated by obsession of distal end sweep just or more elbow Splint, and Ten patients had been treated by: obsession distal end range and DRUJ fixed by (cross over distal Radioulnar K.wire or ulna styloid obsession or both). Aftereffects of obsession of DRUJ and styloid ulna was preferable in result over above elbow brace. Ulnar side wrist agony and torment with lively exercises saw in gathering (1) more than gathering (2). Some patient in gathering (1) was griping of elbow solidness after cast evacuation which settled by physiotherapy. intraoperative obsession of DRUJ prescribed to be done after obsession of the distal range break which is in a way that is better than above elbow projecting.
\end{abstract}

Keyword: Distal Radius, DRUJ instability.

\section{Introduction}

Distal range cracks speak to the $10 \%-12 \%$ of al breaks of the body and as much as $72 \%$ of all lower arm breaks [1].

The injury system is normally a fall on an outstretched hand. A dislodged crack will ordinarily bring about a wrist deformation [2].

There will be torment, constraint of development and delicacy on palpation of the distal span [2].

Distal Radius Fractures might be intra articular or extra articular (colles' crack) [3].

These cracks are generally either non uprooted and stable or dislodged and shaky; some of them might be comminuted and/or include the ulnar or carpal bones. The clinical writing recommends that larger part (about $90 \%$ ) of distal range breaks in more seasoned osteoporotic patients are straightforward extra-articular cracks and there's a decent useful result that can be normal in these patients [3].

In any case, the mending of dislodged intraarticular break is risky [4].

Since the sweep assumes a fundamental part in the steadiness of the wrist joint, conservation of ligamentous capacity of the wrist and the biomechanics of radio carpal and radio ulnar joints, anatomical decrease and remedy of articular surface ambiguity diminishes the capability of degeneration and quickens post-injury recovery. The need of anatomic decrease of these breaks and its connection to useful results has been shown by numerous creators [5].

Distal sweep break is joined by a few entanglements; like distal radio ulnar joint (DRUJ) precariousness, the most incapacitating Complication, is under discussion as to the two its temperament and its need for careful recreation. The frequency of DRUJ insecurity was accounted for to be 10-19\% after distal span break. Both intense Injuries and biomechanical changes identified with ongoing wounds bring about torment and diminishing in radio carpal and radio ulnar scope of motion [4].

The DRUJ jam its security through articular surface congruity and with ordinary capacity of three-sided fibro ligament complex (TFCC). The ulnar head explains with the sigmoid score of the distal span and the congruency between the bones gives some solidness to the DRUJ, anyway this verbalization is shallow and depends on just delicate tissue stabilizers to keep up joint uprightness. The three-sided fibro ligament complex (TFCC) is the most fundamental delicate tissue stabilizer of the DRUJ. The dorsal TFCC Is significant in settling the DRUJ during pronation while the volar TFCC is significant in DRUJ adjustment during supination This Indispensable stabilizer is normally harmed in distal range cracks, But lamentably it is regularly neglected in numerous distal span obsessions and this prompts DRUJ precariousness much of the time [4].

\section{Patients and methods \\ 2.1 Patients}

Twenty patients with fracture distal radius with distal radioulnar joint injury were managed over the past months between July 2019 and September 2020 in Benha University hospital and Shebin Elkom teaching hospital. Criteria of operative treatment: fractures with articular step $>2 \mathrm{~mm}$, dorsal comminution, dorsal angulation $>5^{\circ}$ or $>5 \mathrm{~mm}$ shortening which in closed and recent fractures in adult patients. The mean age of the patients was $(46.6 \pm 11.06)$ years in group 1 and was $(42.5 \pm 13.59)$ in group 2 with a range (22-66). 12 patients were males while 8 were female. 13 patients had the dominant side affected while 7 had the nondominant side affected. The mechanisms of trauma were as follows: Fall on an out stretched hand: 12 
(60\%) high energy injury: 8 (40\%) Fracture type according to Frykman's classification: Type II: 3 patients (15\%). Type IV: 6 patients (30\%). Type VI: 3 patients (15\%). Type VIII: 8 patients $(40 \%)$.

\subsection{Methods}

Patients were evaluated by history taking, physical examination, Radiological evaluation and scoring system (mayo score). The techniques used were Kirschner wires, plate and screws or plate and screws with additional Kirschner wires. Closed Pinning with Kirschner wires were method of Fixation in 10 case. Plate and screws were used in 10 cases. Addition Kirschner wires were needed with plate and screws in 4 cases

DRUJ fixation by [1] transverse k.wire was placed thru distal ulna into the reduced distal radius with forearm in supination [2] open reduction and K.wire fixation of ulna styloid base fracture [3] transverse k.wire and ulna styloid fixation. After surgery, a long arm splint was applied with the forearm in $30^{\circ}$ supination for 6 weeks for patients with DRUJ instability with DER fixation only. Short arm splint was applied with the forearm in neutral position for 6 weeks for patients with DRUJ instability with DER fixation and DRUJ fixation. Physiotherapy for edema control and finger motion was started on the day of surgery. Active and passive motion of the wrist was initiated under the supervision of the surgeon 6 weeks after surgery for 10 times per session and three sessions per day.

\section{Results}

During the period between July 2019 and September 2020, a prospective study was performed to assess outcomes in treatment of distal radio ulnar joint injuries with distal radius fractures. Twenty patients were enrolled in the study (12 males and 8 females).

\begin{tabular}{|c|c|c|c|c|c|c|}
\hline \multirow[t]{2}{*}{ Demographic data } & \multicolumn{2}{|c|}{$\begin{array}{l}\text { Group(1) } \\
n=10\end{array}$} & \multicolumn{2}{|c|}{$\begin{array}{c}\text { Group(1) } \\
\mathbf{n}=\mathbf{1 0}\end{array}$} & \multirow[t]{2}{*}{$\begin{array}{c}\text { Fisher } \\
\text { exact test }\end{array}$} & \multirow[t]{2}{*}{$P$ value } \\
\hline & No & $\%$ & No & $\%$ & & \\
\hline Sex & & & & & 0.833 & 0.359 \\
\hline Male & 7 & $70.0 \%$ & 5 & $50.0 \%$ & & \\
\hline Female & 3 & $30.0 \%$ & 5 & $50.0 \%$ & & \\
\hline Age & & & & & t-test & 0.469 \\
\hline Mean \pm SD & & 11.06 & & 13.59 & 0.74 & \\
\hline \multirow[t]{2}{*}{ DRUJ } & \multicolumn{2}{|c|}{$\begin{array}{c}\text { Group (1) } \\
\mathbf{n}=\mathbf{1 0} \\
\end{array}$} & \multicolumn{2}{|c|}{$\begin{array}{c}\text { Group (2) } \\
\mathbf{n}=\mathbf{1 0} \\
\end{array}$} & $\begin{array}{c}\text { Fisher } \\
\text { exact test }\end{array}$ & $P$ value \\
\hline & No & $\%$ & No & $\%$ & & \\
\hline Long arm splint & 10 & $100 \%$ & 0 & $100 \%$ & 20.0 & 0.001 \\
\hline Transverse k.wires & 0 & $0 \%$ & 4 & $40 \%$ & & \\
\hline $\begin{array}{l}\text { Transverse k.wires and ulna } \\
\text { styloid fixation }\end{array}$ & 0 & $0 \%$ & 4 & $40 \%$ & & \\
\hline Ulna styloid fixation & 0 & $0 \%$ & 2 & $20 \%$ & & \\
\hline
\end{tabular}

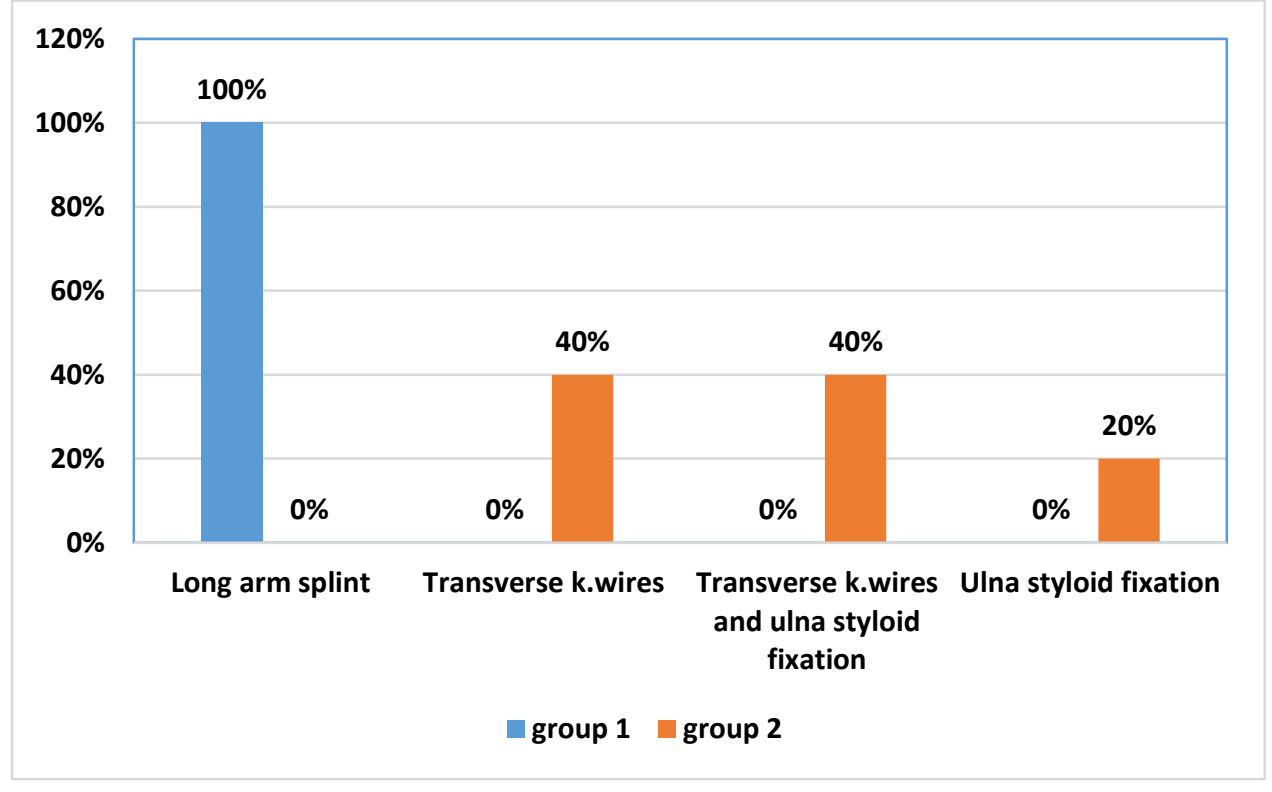

Fig (1) frequency of group (1) and group (2) 
Table (1) Comparison between the studied groups regarding criteria of fracture.

\begin{tabular}{|c|c|c|c|c|c|c|}
\hline \multirow[t]{2}{*}{ Criteria of fracture } & \multicolumn{2}{|c|}{$\begin{array}{c}\text { Group (1) } \\
\mathbf{n}=10\end{array}$} & \multicolumn{2}{|c|}{$\begin{array}{c}\text { Group (2) } \\
n=10\end{array}$} & \multirow[t]{2}{*}{$\begin{array}{c}\text { Fisher } \\
\text { exact test }\end{array}$} & \multirow[t]{2}{*}{$P$ value } \\
\hline & No & $\%$ & No & $\%$ & & \\
\hline Site of fracture & & & & & Fisher's & 0.29 \\
\hline Dominant hand & 6 & $60.0 \%$ & 7 & $70.0 \%$ & Exact Test & \\
\hline Non dominant hand & 4 & $40.0 \%$ & 3 & $30.0 \%$ & 0.220 & \\
\hline Mode of trauma & & & & & Fisher's & 0.075 \\
\hline High energy & 2 & $20.0 \%$ & 6 & $60.0 \%$ & Exact Test & \\
\hline FOSH & 8 & $80.0 \%$ & 4 & $40.0 \%$ & 3.33 & \\
\hline Type of fracture frykman & & & & & 0.667 & 0.881 \\
\hline II & 2 & $20.0 \%$ & 1 & $10.0 \%$ & & \\
\hline IV & 3 & $30.0 \%$ & 3 & $30.0 \%$ & & \\
\hline VI & 1 & $10.0 \%$ & 2 & $20.0 \%$ & & \\
\hline VIII & 4 & $40.0 \%$ & 4 & $40.0 \%$ & & \\
\hline Type of fixation & & & & & Fisher's & 0.653 \\
\hline k.wires & 5 & $50.0 \%$ & 4 & $40.0 \%$ & Exact Test & \\
\hline Plate and screws & 5 & $50.0 \%$ & 6 & $60.0 \%$ & 0.202 & \\
\hline $\begin{array}{l}\text { Union time and k.wires or cast } \\
\text { removal }\end{array}$ & & & & & 1.2 & 0.549 \\
\hline 6 weeks & 7 & $70.0 \%$ & 7 & $70.0 \%$ & & \\
\hline 7 weeks & 3 & $30.0 \%$ & 2 & $20.0 \%$ & & \\
\hline 8 weeks & 0 & $0.0 \%$ & 1 & $10.0 \%$ & & \\
\hline
\end{tabular}

$*_{p}$ value $\leq 0.05$ is statistically significant.

Table (2 )Comparison between the studied groups regarding follow up outcome according to Mayo wrist scoring at $3^{\text {rd }}$ month.

\begin{tabular}{|c|c|c|c|c|c|c|}
\hline \multirow[t]{2}{*}{$\begin{array}{l}\text { Post-operative outcome } \\
\text { (Mayo wrist scoring ) }\end{array}$} & \multicolumn{2}{|c|}{$\begin{array}{c}\operatorname{group}(\mathbf{1}) \\
\mathbf{n}=\mathbf{1 0} \\
\end{array}$} & \multicolumn{2}{|c|}{$\begin{array}{c}\operatorname{group}(2) \\
n=10\end{array}$} & \multirow[t]{2}{*}{$\begin{array}{c}\text { Fisher } \\
\text { exact test }\end{array}$} & \multirow[t]{2}{*}{$P$ value } \\
\hline & No & $\%$ & No & $\%$ & & \\
\hline Scoring system & & & & & 7.58 & 0.023 \\
\hline Excellent & 1 & $10.0 \%$ & 2 & $20.0 \%$ & & \\
\hline Good & 5 & $50.0 \%$ & 7 & $70.0 \%$ & & \\
\hline Satisfactory & 4 & $40.0 \%$ & 1 & $10.0 \%$ & & \\
\hline
\end{tabular}

Table ( 3) Comparison between the studied groups regarding follow up outcome according to Mayo wrist scoring at $6^{\text {th }}$ month.

\begin{tabular}{lcccccc}
\hline $\begin{array}{l}\text { Post-operative outcome } \\
\text { (Mayo wrist scoring ) }\end{array}$ & \multicolumn{2}{c}{$\begin{array}{c}\text { group(1) } \\
\mathbf{n = 1 0}\end{array}$} & \multicolumn{2}{c}{$\begin{array}{c}\text { group(2) } \\
\mathbf{n = 1 0}\end{array}$} & \multirow{2}{*}{$\begin{array}{c}\text { Fisher } \\
\text { exact test }\end{array}$} & P value \\
\cline { 2 - 5 } & No & \% & No & \% & & \\
\hline Scoring system & & & & & 8.02 & 0.018 \\
Excellent & 3 & 30 & 9 & 90 & & \\
Good & 3 & 30 & 1 & 10 & & \\
Satisfactory & 4 & 60 & 0 & 0 & & \\
\hline
\end{tabular}

Results of fixation of DRUJ \& styloid ulna was better in outcome than above elbow splint Ulnar side wrist pain and pain with vigorous activities noticed in group (1) more than group (2) Some patient in group (1) was complaining of elbow stiffness after cast removal which resolved by physiotherapy

\section{Case Presentation}

4.1Case (1)

Male patient 28 years old RTA had recent distal radius fracture with unstable DRUJ fixed by plate and screws and above elbow cast 


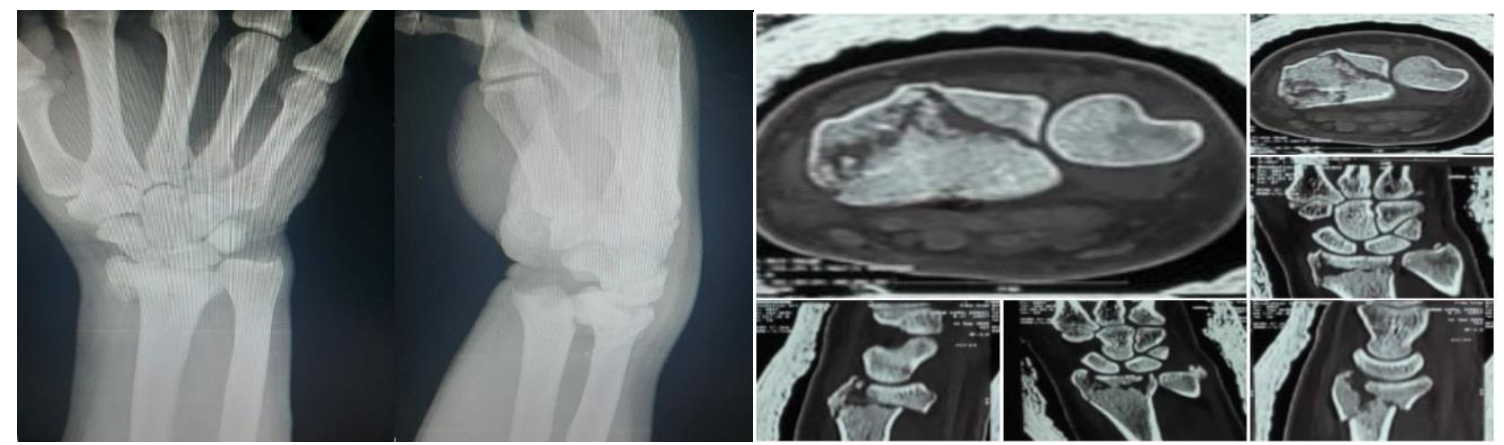

Case (1) preoperative x-ray and C.T.

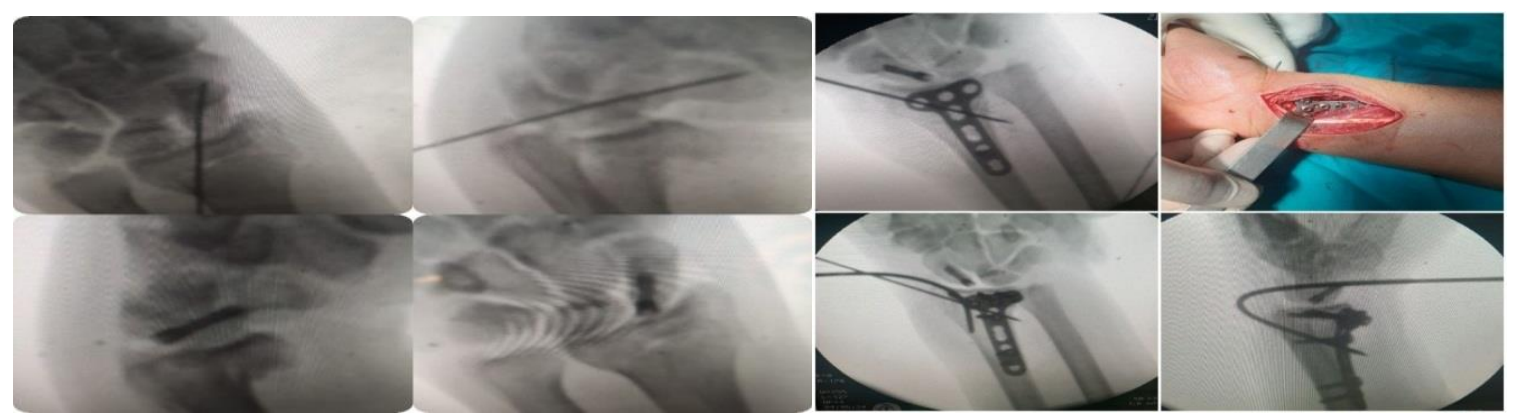

Case (1) intraoperative x-ray and phot.

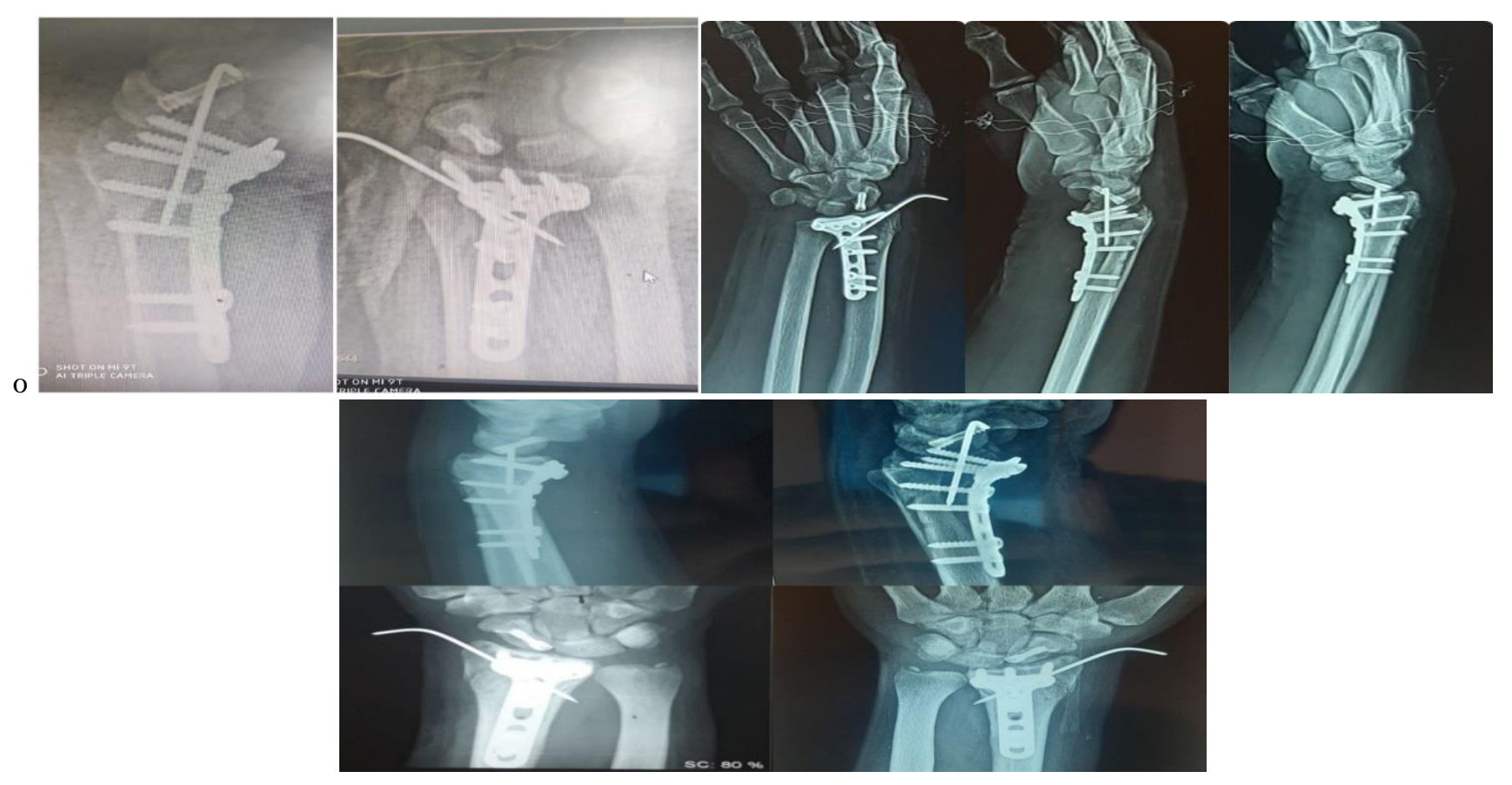

Case (1) post-operative.

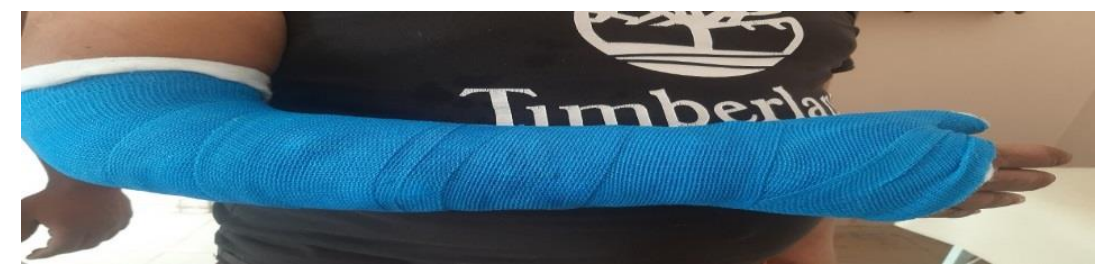

Case (1) post-operative at $3^{\text {rd }}$ week 


\subsection{Case (2)}

Male patient 29 years old had distal radius fracture with fracture styloid ulna and unstable DRUJ fixed by
Plate and screws for distal radius and ORIF by K.wire for ulna styloid and transverse K.wire for DRUJ

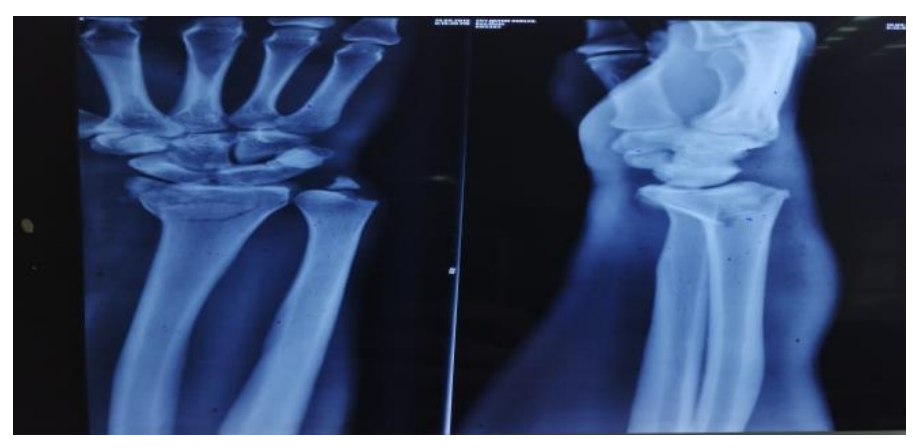

Case (2) preoperative

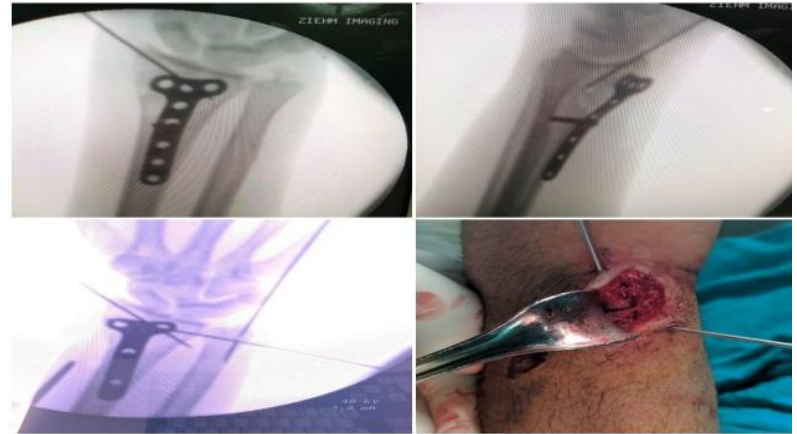

Case (2) intra-operative

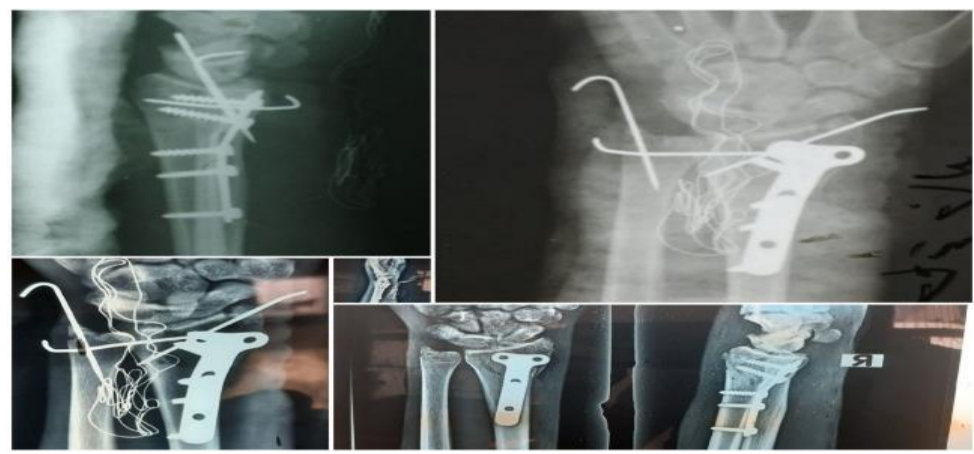

Case (2) post-operative

4.3 Case (3) Female patient 48 years old fell on outstretched hand and had distal radius fracture with unstable DRUJ by k.wires.

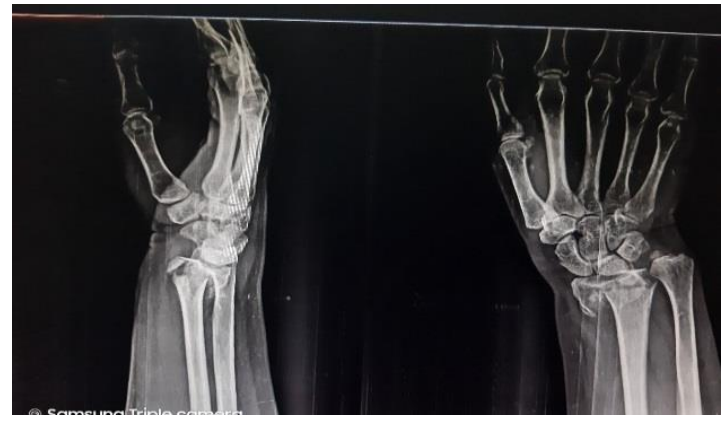

Case (3) preoperative

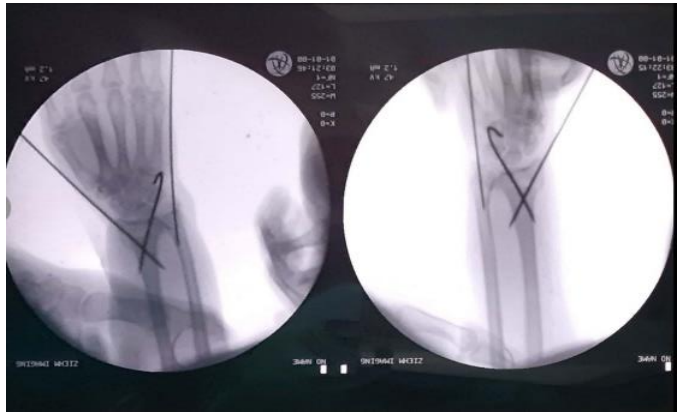

Case (3) intra-operative

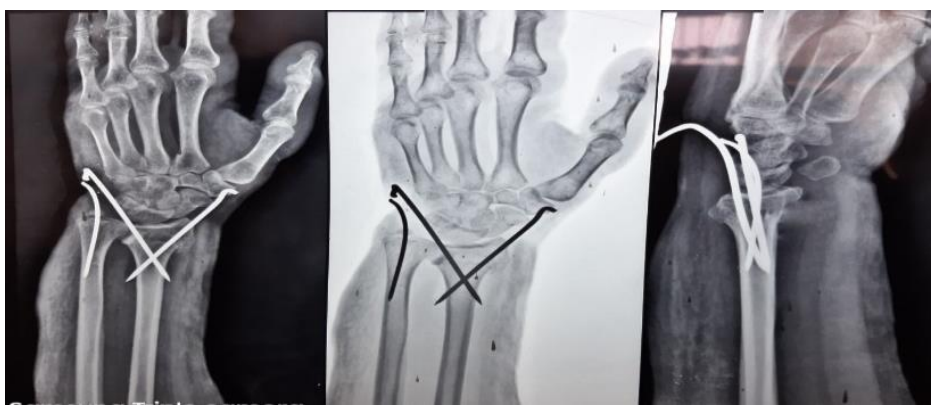

Case(3) post-operative. 


\section{Discussion}

DRUJ shakiness is a significant reason for ulnarsided wrist torment after hard recuperating of distal sweep cracks. The components related with this injury, notwithstanding, infrequently have been examined. On account of its anatomic closeness to the three-sided fibro ligament complex, crack of the ulnar styloid at its base has been proposed to cause DRUJ shakiness. Nonetheless, all around planned investigations reliably denied the relationship between suggestive DRUJ unsteadiness and the ulnar styloid crack in distal span breaks [6].

In our investigation Ulnar styloid cracks had an extraordinary part in the DRUJ steadiness and this was measurably huge and these outcomes was like outcomes acquired by Lindau et al., 2000a; May et al., 2002; Sammer and Chung, 2012 and . Stoffelen et al. who assessed 272 distal outspread cracks in a planned report. They inferred that a separated ulnar styloid added to helpless outcomes and this impact is a result of distal radioulnar joint association, however they made no notice of the technique for crack obsession in their arrangement.

On the opposite side Richards et al. assessed 118 cases with distal sweep crack arthroscopically and found that ulnar styloid break didn't influence TFCC and presumed that ulnar styloid break didn't foresee TFCC injury [4] Sammer et al 2009 assessed the result of ulnar styloid breaks without DRUJ shakiness dependent on understanding evaluated measures subsequent to treating distal outspread crack with ORIF. 88 cases out of 144 had simultaneous ulnar styloid break. These patients were treated with ORIF of the distal sweep. The creators followed up patients for one year and assessed the outcomes utilizing the Michigan hand results survey (MHQ). They found that no patients had DRUJ shakiness [4 ] It is imperative to accentuate that Richards et al's. discoveries are more careful, since they inspected the patients arthroscopically. Untreated stable or insignificantly dislodged ulnar styloid crack joined by distal range break, had no unfriendly impact on the soundness of the DRUJ after ORIF of the span. . [4].

(4) announced in their long haul development of untreated TFCC wounds that grasp quality is less fortunate, in spite of the fact that they found that different evaluations, including persistent detailed results, were unaffected [4]. Moreover, a few creators have distinguished DRUJ flimsiness as a helpless prognostic factor in DRFs [5]. Following on from this, Ruch et al. detailed that arthroscopic TFCC fix and 3 weeks of immobilization in supination related to outer obsession of the DRF, brought about no ulnar-sided wrist torment [6].Conversely, others have announced that non-usable treatment of the ulnar styloid break or intense DRUJ [7].

The clinician ought to likewise give specific consideration to reestablishing spiral length and accomplishing sufficient decrease of the sigmoid-score articular surface. A high extent of unsuitable treatment results following malunion of the distal range come about because of shortening of the sweep, with a related gained positive ulnar difference. Ulnocarpal impaction disorder may result. Knirk and Jupiter have archived helpless outcomes in distal spiral cracks when relocation of the radio carpal articular surface is more prominent than $1 \mathrm{~mm}$. No information are yet accessible that demonstrates whether the DRUJ articular surface is any more open minded toward articular surface relocation [8].

It is imperative to realize how changes in the direction of the distal sweep influence contact at the DRUJ. There is proof that DRUJ contact power is identified with the direction of the outspread articular surface or sigmoid score. Be that as it may, there has been no methodical investigation indicating the connection between distal range direction and DRUJ contact [9].

Regardless of these discoveries a few creators have exhibited that a going with ulnar styloid crack was an indicator of helpless outcomes [4].

Interestingly, Lindau et al. propose that the presence of a ulnar styloid separation break may be a sign of TFCC injury [4].

High energy wounds may influence the DRUJ soundness and this was like kown et al 2012 who found the presence of an open injury expanded the danger of DRUJ insecurity in distal sweep cracks. Given that open injuries for the most part are identified with a high-energy injury, it appears to be likely that a highenergy injury would go about as a puzzling component connecting with an open injury and DRUJ precariousness. In any case, the presence of high energy wounds was comparative between the gatherings, maybe inferable from a deficient number of patients. Further investigation with satisfactory force is important to evaluate the part of a high-energy injury in regards to DRUJ unsteadiness in distal span cracks.

\section{Conclusion}

DRUJ precariousness is a significant intricacy after distal span crack so intraoperative obsession of DRUJ prescribed to be done after obsession of the distal sweep break which is in a way that is better than above elbow projecting.

\section{References}

[1] W.J. Qiu, Y.F. Li, Y.H. Ji, The comparative risk of developing postoperative complications in patients with distal radius fractures following different treatment modalities. Sci Rep.; 5,Vol.15, PP.318,2015.

[2] H.D. Kvernmo, Y.Krukhaug ,Treatment of distal radius fractures. Tidsskrift for den Norske laegeforening: tidsskrift for praktisk medicin, ny raekke,Vol.133(4), PP.405-11,2013.

[3] J.B. Jupiter, Fractures of the distal radius. Instructional course lectures ,Vol. 41, PP.1323,1992 . 
[4] G.H. Kazemian, H. Bakhshi, M. Lilley, DRUJ instability after distal radius fracture: a comparison between cases with and without ulnar styloid fracture. International journal of surgery (London, England),Vol.9(8),PP.648-51,2011.

[5] R.J. MacFarlane, D. Miller, L. Wilson, Functional Outcome and Complications at 2.5 Years Following Volar Locking Plate Fixation of Distal Radius Fractures. Journal of hand and microsurgery ,Vol.7(1),PP.18-24,2015.

[6] B.C Kwon. , B.K. Seo, H.J. Im, Clinical and radiographic factors associated with distal radioulnar joint instability in distal radius fractures. Clinical Orthopaedics and Related Research®, Vol.470(11),PP.3171-9,2012.
[7] H. Gong, H. Cho, J .Kim, Surgical treatment of acute distal radioulnar joint instability associated with distal radius fractures. Journal of Hand Surgery (European Volume),Vol.40(8), PP.7839,2015.

[8] Chidgey LK. The distal radioulnar joint: problems and solutions. JAAOS-Journal of the American Academy of Orthopaedic Surgeons, Vol.3(2), PP.95-109, 1995.

[9] D. Greybe, M.R.Boland, T. Wu, Examining the influence of distal radius orientation on distal radioulnar joint contact using a finite element model. International Journal for Numerical Methods in Biomedical Engineering, Vol.32,pp 